\title{
Normas de publicación para los colaboradores
}

I. Sobre el tipo de contribución

- Artículos inéditos (hasta 30 folios de 30 líneas por 70 toques, o aproximadamente 60.000 caracteres, incluyendo referencias bibliográficas y notas).

- Ensayos bibliográficos (hasta 12 folios de 30 líneas por 70 toques, o aproximadamente 25.200 caracteres, incluyendo referencias bibliográficas y notas): reseñas críticas de un libro o de varios libros tratando asuntos correlativos.

- Reseñas bibliográficas (hasta 6 folios de 30 líneas por 70 toques, ó 6.300 caracteres): pequeñas reseñas de libros recientes.

2. Sobre la evaluación para publicación

- La revista publica artículos en portugués, inglés y español, aceptando envíos en francés, cuya publicación dependerá de la posibilidad de traducción.

- Los originales de artículos, ensayos y reseñas enviados a la revista serán leídos primeramente por los editores que, si consideran que están de acuerdo con la política editorial de la revista y que cumplen los requisitos académicos indispensables, los enviarán para dictámenes de por lo menos dos especialistas en la materia, garantizando el anonimato de autores y evaluadores (sistema de revisión por pares a "doble ciego").

- Los dictaminadores deberán analizar el contenido, la relevancia y la calidad de las contribuciones, considerando redacción, originalidad 
del texto, calidad del argumento y de la bibliografía, pertinencia y adecuación de la metodología empleada. El resultado de la evaluación puede ser: a) aceptar, b) aceptar con revisiones, c) reformular y presentar nuevamente y d) no aceptar. En casos de un parecer positivo y uno negativo, el trabajo será sometido a un tercer dictamen. Cuando haya necesidad de modificaciones solamente referentes a aspectos gramaticales, ortográficos y normativos, para mantener la homogeneidad de la publicación, los editores se reservan el derecho de hacer las modificaciones necesarias, respetando el estilo del autor.

3. Cada artículo debe incluir un resumen conteniendo de 100 a 150 palabras, en portugués y en inglés, con 3 a 5 palabras clave. Los autores deben enviar sus datos profesionales (institución, cargo, título, principales publicaciones), dirección para correspondencia y correo electrónico. Estos datos deben aparecer en una página separada, conteniendo también el título del trabajo.

4. Las notas de pie se deben indicar con números arábigos en orden creciente al final de cada página y deben contener información de naturaleza sustantiva, no deben ser simples referencias bibliográficas.

5. Las citaciones y las referencias bibliográficas deben aparecer en el cuerpo del texto con el siguiente formato:

- (apellido del autor, año de publicación, página), según el ejemplo: (WAGLEY, 1977, p. 160-162).

6. Las referencias bibliográficas, en orden alfabético, deben estar al final del trabajo y respetar el formato que aparece en los siguientes ejemplos (se solicita atención a la puntuación, espacios, negrita y uso de mayúscula):

- Libro:

VEBLEN, T. A teoria da classe ociosa. São Paulo: Livraria Pioneira, 1965.

- Colección:

LIPSET, S. M. (org.). Política e Ciências Sociais. Rio de Janeiro: Zahar, 1972.

- Artículo en colección:

WALLERSTEIN, I. Three Ideologies or One? The Pseudo-Battle of Modernity. In: TURNER, S. P. (org.). Social Theory \& Sociology. The Classics and Beyond. Oxford: Blackwell, 1996.

- Artículo en periódico:

PAIXÃO, A. L. A teoria geral da ação e a arte da controvérsia. Revista Brasileira de Ciências Sociais, São Paulo, v. 4, n. 11, p. 34-56, out. 1989. 
- Tesis y disertación académicas:

MIGUEL, S. M. Um olhar para dentro: o movimento feminista no Rio de Janeiro. Florianópolis. Disertación (Maestría en Sociología Política). Universidade Federal de Santa Catarina, 1988.

7. Los gráficos, figuras, tablas, cuadros o mapas se deben introducir correctamente en el texto, numerados, con título y con la debida referencia. Deben estar confeccionados de manera tal que permita su reproducción directa.

8. Los ensayos bibliográficos y reseñas deben incluir las referencias completas de las obras analizadas, indicando el número de páginas de cada una.

9. El envío de cualquier colaboración implica la cesión total de los derechos autorales a la revista Política y Sociedad. Una nueva publicación del mismo texto, siendo iniciativa de su autor o de terceros, está sujeta a la expresa mención de la precedencia de su publicación en este periódico, citándose la edición y fecha de esta publicación. La revista no se compromete a devolver los originales de las colaboraciones enviadas.

10. Las opiniones expresadas en los artículos firmados son de la exclusiva responsabilidad de sus autores.

I I. Los autores deben enviar sus textos preferentemente a través del sitio de la revista (http://www.periodicos.ufsc.br/index.php/politica) o en formato electrónico (Microsoft Word, OpenOffice o RTF) que no supere los $2 \mathrm{MB}$, a la dirección ps@cfh.ufsc.br.

\section{Para obtener más información, solicítela al Programa de Post Grado en Sociología Política:}

Tel.+55 48 3721-9253

Fax +5548 3721-9098

Dirección electrónica: ppgsp@cfh.ufsc.br

Portal electrónico: http://www.sociologia.ufsc.br 


\section{Condiciones para el envío}

Como parte del proceso de envío, los autores deben verificar la conformidad del envío con respecto a todos los ítems enumerados a continuación. Los envíos que no estén de acuerdo con las normas se devolverán a sus autores.

I. La contribución es original e inédita, y no está en evaluación para publicación en otra revista; caso contrario, justificar en "Comentarios al Editor".

2. Los archivos e enviar están en formato Microsoft Word, OpenOffice o RTF (no deben pasar de los 2MB)

3. Todas las direcciones de páginas de Internet (URLs), incluidas en el texto (Ej.: http://www.ibict.br) están activas para hacer clic.

4. El texto está en espacio simple; usa una fuente de 12 puntos; emplea itálico en lugar de subrayar (excepto en direcciones URL); con figuras y tablas incluidas en el texto, y no al final.

5. El texto obedece a los estándares de estilo y requisitos bibliográficos descritos en las Normas de publicación para los colabores.

6. La identificación del autor de este trabajo fue retirada del archivo y de la opción Propiedades en Word, asegurando de esta manera el criterio de confidencialidad de la revista. 